\title{
Undergraduates and Their Use of Social Media: Assessing Influence on Research Skills
}

\author{
Kanelechi C.K. Nwangwa ${ }^{1,2, *}$, Ebun Yonlonfoun ${ }^{3}$, Tope Omotere ${ }^{4}$ \\ ${ }^{1}$ Department of Education, Eastern Nigeria Union Mission, Abia State, Nigeria \\ ${ }^{2}$ ASTEC, Owerrinta, Via Aba, Isiala Ngwa South LGA, Abia State, Nigeria \\ ${ }^{3}$ Department of Educational Management, Tai Solarin University of Education, Ogun State, Nigeria \\ ${ }^{4}$ Department of History \& International Studies, University of Ilorin, Kwara State, Nigeria \\ *Corresponding Author: kcknwangwa@gmail.com
}

Copyright (C) 2014 Horizon Research Publishing All rights reserved.

\begin{abstract}
This research investigates the influence of social media usage on research skills of undergraduates offering Educational Management at six different universities randomly selected from the six geo-political zones in Nigeria. Various studies on the effects of social media on students have concentrated mainly on academic performance (Kirschner \& Karpinski, 2010; Oluwatoyin 2011; and Ogedebe, Emmanuel, \& Musa, 2012). This research shifts its attention away from this and rather focuses on how social media influences core research skills of undergraduates. The identified areas include how it influences their ability to source for quality research materials; generate ideas about areas of research interest; and develop creative writing skills. Questionnaire was developed to explore the participating students' views regarding social media, their adoption of social media for research purpose, and the influence of social media on their research skills. The population consisted of six hundred (600) students from six universities comprising male and female respondents. Data was analysed using descriptive analysis and frequency. Chi-square (X2) was used to test the only null hypothesis in the study. The findings of this paper indicate that undergraduates frequently copy from Wikipedia as their major source of information; uses Facebook to generate ideas from colleagues about their research focus; and make use of Wordpress or Blogger to develop their creative writing skills. However, students' reliance on these social media tools alone has resulted in their dwindling research skills to produce quality research works. Recommendations were made on how to improve students' research skills.
\end{abstract}

Keywords Educational Management, Research Skills, Social Media, Undergraduates, Nigeria

\section{Introduction}

Research writing is core to undergraduates' graduation requirements. Hence, students are expected to acquire research skills before they graduate. When students lack research skills, it is inevitable that they will experience difficulties in their postgraduate studies as well as their chosen occupation. Unfortunately, many students are characterised by a lack of good research skills. This is manifested by, inter alia, their incapability to effectively use the library, source for quality academic works online or take meaningful notes during field work. More recently, studies have shown that students have turn to the use of social media as their primary means of communication, so much that when they use the e-Library for research, they soon forget their purpose of going online and start updating their status on social networking sites (SNSs). Farzana, Mushahid \& Mahe (2010) sought information from 95 University students on the purpose of using social media. It was found that most of them were frequently using these social media for making friends and rarely used for research work.

A growing number of Nigerian scholars agree that addiction to social media sites are potentially a disruptive technology to students' academic work in higher education. Among them is Oluwatoyin (2011: 13) who surveyed 1,860 Facebook users from the Lagos State University and found that most of the students could not get cumulative grade point average (CGPA) above 3.50 because they've spent large part of their time on social media than on their home work and study time which could contribute to higher grade. Oluwatoyin's findings is further supported by Ajewole and Fasola (2011: 69) whose study of 884 students from eight higher institutions in Oyo State showed that majority of them spend more time on social media at the detriment of their studies.

This view is however rejected by some researchers who acknowledge that social media sites not only re-engage learners with their studies but also enhance their academic performance. For instance, Onyeka, Sajoh \& Bulus (2013:39) argue that the frequent use of social media sites has no negative effect on the students' studies. In the same vein, Ogedebe, Emmanuel \& Musa (2012: 788) posited that 
Facebook usage does not have adverse effect on the academic work of students in the Universities.

While the present study is not burdened with the direct effect of social media usage on undergraduates' CGPA, its primary focus is centered on the effects of students' adoption of social media on their research skills. This issue is being investigated in order: to determine whether the current practices of students on social media sites disrupts their research skills or enhance the same; contribute to the emerging studies on the use of social media for academic purpose; and to provide policy recommendations for the National University Commission (NUC) as well as university officials to explore ways by which social media software could be used for research purpose in Nigerian universities.

\section{Social Media Use by Students}

The definition of social media is "the relationships that exist between network of people" (Qingya, Wei \& Yu, 2011: $3)$. Social media emerged as a term frequently used to describe different types of electronic communication platforms. The availability of high speed internet broadband connection with massive use of desktop computers, laptops, e-readers, tablets and smart phones enable millions of undergraduates to actively engage in social networking, text messaging, blogging, content sharing, online learning, and much more.

Social media, as defined by Bryer and Zavatarro (2011: 327), "are technologies that facilitate social interaction, make possible collaboration, and enable deliberation across stakeholders". These technologies now include blogs, wikis, media (audio, photo, video, text) sharing tools, networking platforms, and virtual worlds. Social Media Online (2011) defines social media as primarily internet-and mobile-based tools for sharing and discussing information by users. The term, according to Andreas and Michael (2010: 61), refers to "a group of Internet-based applications that build on the ideological and technological foundations of Web 2.0, and that allow the creation and exchange of user-generated content." Web 2.0 was coined by Darcy DiNucci in 1999 to describe interactive social websites which allow users to interact and collaborate with each other in a social media dialogue.

For simplicity purpose, we regard social media as comprising online applications for social networking sites, social bookmarking and sharing tools, social citation tools, blogging and microblogging tools, virtual worlds, e-conference presentation sharing tools, audio and video tools, e-project management tools, and research and writing collaboration tools; primarily developed to foster user-centered social interaction. By this definition, social media could be categorized into eight areas that are inter-dependent by their mode of usage. Examples of sites listed are not exhaustive. 


\section{Category of Social Media}

\begin{tabular}{|c|c|c|}
\hline $\mathrm{S} / \mathrm{N}$ & Category of Social Media & Example \\
\hline 1 & Social Networking Sites (SNS) & $\begin{array}{c}\text { Facebook - www.facebook.com (Facebook is a social utility that connects people with friends } \\
\text { and others who work, study and live around them, even if they are in other countries). } \\
\text { LinkedIn - www.linkedin.com (LinkedIn is a social networking website for people in } \\
\text { professional occupations.) } \\
\text { ResearchGate - www.researchgate.net (This is a social networking site for scientists and } \\
\text { researchers to share papers, ask and answer questions, and find collaborators) } \\
\text { Academia - www.academia.edu (Academics use the platform to share their research, monitor } \\
\text { deep analytics around the impact of their research, and track the research of academics they } \\
\text { follow) }\end{array}$ \\
\hline 2 & Social Bookmarking and Sharing Tools & $\begin{array}{l}\text { CiteULike - www.citeulike.com (This social bookmarking site allows users to save and share } \\
\text { citations of academic papers amongst researchers). } \\
\text { Delicious - www.delicious.com (This is a social bookmarking web service for storing, sharing, } \\
\text { and discovering web bookmarks). } \\
\text { Digg - www.digg.com (This is a news aggregator site that share the most interesting and talked } \\
\text { about stories, videos and pictures on the web). } \\
\text { Reddit - www.reddit.com (Reddit, stylized as reddit, is a social news and entertainment website } \\
\text { where registered users submit content in the form of either a link or a text post of either a link or } \\
\text { a text post). }\end{array}$ \\
\hline 3 & Blogging and Microblogging Tools & $\begin{array}{l}\text { Blogger - www.blogger.com (This is a weblog publishing service from Google, for sharing text, } \\
\text { photos and video). } \\
\text { Wordpress - www.wordpress.org (It's an open source blogging tool and a content-management } \\
\text { system (CMS) based on PHP and MySQL, which runs on a web hosting service). } \\
\text { Tumblr - www.tumblr.com (This is a microblogging platform and social networking service that } \\
\text { allow users to post multimedia and other content to a short-form blog) } \\
\text { Twitter - www.twitter.com (This is an online social networking site and microblogging service } \\
\text { that enables users to send and read "tweets", which are text messages limited to } 140 \text { characters. } \\
\text { Registered users can read and post tweets but unregistered users can only read them) }\end{array}$ \\
\hline 4 & Virtual Worlds & $\begin{array}{l}\text { Second Life-www.secondlife.com (This is a free 3D virtual world where users can socialize, } \\
\text { connect and create using free voice and text chat) } \\
\text { OpenSim - www.opensimulator.org (This is an open source multi-platform, multi-user 3D } \\
\text { application server. It can be used to create a virtual environment (or world) which can be } \\
\text { accessed through a variety of clients, on multiple protocols. It allows virtual world developers to } \\
\text { customize their worlds using the technologies they feel work best). }\end{array}$ \\
\hline 5 & Presentation Sharing Tools & $\begin{array}{c}\text { Scribd - www.scribd.com (This is a digital documents library that allows users to publish, } \\
\text { discover and discuss original writings and documents in various languages using their iPhone, } \\
\text { iPad, Kindle Fire and Nook tablet). } \\
\text { SlideShare - www.slideshare.net (This platform allow the sharing of information in PowerPoint, } \\
\text { OpenOffice presentations, Keynote, PDF and infographics). } \\
\text { Sliderocket - www.sliderocket.com (SlideRocket is an online presentation platform that let users } \\
\text { create, manage, share and measure presentations). }\end{array}$ \\
\hline 6 & Audio and Video Sharing Tools & $\begin{array}{l}\text { YouTube - www.youtube.com (YouTube is a video-sharing website which allow users to share } \\
\text { their videos with friends, family, and the world. } \\
\text { Flickr - www.flickr.com ( This is an image and video hosting website with large pool of picture } \\
\text { galleries available with social networking, chat, groups, and photo ratings). } \\
\text { Livestream - www.livestream.com (This is a live streaming video platform that allows users to } \\
\text { view and broadcast video content using a camera and a computer through the internet). }\end{array}$ \\
\hline 7 & $\begin{array}{c}\text { Research and Writing Collaboration } \\
\text { Tools }\end{array}$ & $\begin{array}{l}\text { PBworks - www.pbworks.com/education (PBworks is a commercial real-time collaborative } \\
\text { editing system that allow users to capture knowledge, share files, and manage projects within a } \\
\text { secure, reliable virtual environment). } \\
\text { Wikispaces - www.wikispaces.com (The section of this social site allow teachers to create a } \\
\text { classroom workspace where the teacher and students can communicate and work on writing } \\
\text { projects alone or in teams). } \\
\text { Wikipedia: } w w w \text {. en.wikipedia.org Wikipedia is a free online encyclopedia, written } \\
\text { collaboratively by the people who use it. It is a special type of website designed to make } \\
\text { collaboration easy, called a wiki. Jimmy Wales and Larry Sanger launched Wikipedia on } \\
\text { January 15, 2001, the latter creating its name, wiki (quick) and encyclopedia. }\end{array}$ \\
\hline 8 & $\begin{array}{l}\text { Project Management, Meeting and } \\
\text { Collaboration Tools }\end{array}$ & $\begin{array}{l}\text { BigBlueButton - www.bigbluebutton.org (It is built for online learning. BigBlueButton enables } \\
\text { universities and colleges to deliver a high-quality learning experience to remote students). } \\
\text { Skype - www.skype.com (The service allows users to communicate with peers by voice using a } \\
\text { microphone, video by using a webcam, and instant messaging over the Internet. Phone calls may } \\
\text { be placed to recipients on the traditional telephone networks) }\end{array}$ \\
\hline
\end{tabular}


Recent surveys have revealed that a growing number of today's undergraduates often referred to as "Net Generation" students (those born between 1980 and 1989) consumed approximately 9 hours of social media per day with most of them using social network sites (SNS) with Blogging and Microblogging tools (Rosen, 2011, Cabral, 2011). Prensky (2001:1) describes them to be heavily involved in computer games, email, the Internet, cell phones and instant messaging as parts of their lives. To Prensky, this group of students functions best when networked. They prefer games to "serious" work (p. 2). The "I Generation" (those born between 1990 and 1999) even consume more time on social media particularly on chatting platforms such as Facebook Chat, 2GO and Google Chat than they do with their friends Face-to-Face. These two 'generations' spend more time on social media than the "Generation X" (those born between 1965 and 1979) who spend approximately from 20 minutes to 3 hours on social media (Rosen, 2011).

By implication, most undergraduates running full time programmes in Nigerian universities spend more time on social media than any other activity of the day, including academic work. In fact, several web statistics testify that large proportion of young people check their Facebook when they first wake up-even before going to the bathroom (www.qbeemedia.com/facts). In order words, as students become addicted to social media, it split their attention, causing massive decrease in knowledge retention (Junco \& Cotten, 2012).

\section{Undergraduate Research Writing}

Research, from the medieval French word, rechercher means "to seek closely." According to Wayne, Gregory \& Joseph (2009: 10) research is when information is gathered to answer a question that solves a problem. To Creswell (2008), "research is a process of steps used to collect and analyze information to increase our understanding of a topic or issue". It consists of three steps: pose a question, collect data to answer the question, and present an answer to the question (Creswell, 2008). Going by this definition, it means that research is not just gathering of information or rearranging of paragraphs from encyclopeadia or web pages but asking real questions and finding solutions to them.

In tertiary education, it is not only postgraduate students or the lecturers that carry out research. Undergraduates too engage in serious academic research. In the book, Research Skill Development and Assessment in the Curriculum, the authors contend that:

Hence, undergraduate research is an inquiry or investigation conducted by an undergraduate that makes an original, intellectual, or creative contribution to the discipline (Wenzel, 2000: 293). This definition makes room for creativity in undergraduate research. Creativity is the ability to transcend mainstream ideas, bringing about originality. It has been identified as the first necessary skill in research writing. Creativity is an essential trait that undergraduate researchers should seek to develop and utilize within their research experience (Adrienne, et al, 2013: 16).

Saron (2005:1) sees undergraduate research as a form of assessment, designed by lecturers to test student skills in locating and organizing materials, comprehending a topic, and/or applying a concept to a specific context (Sharon, 2005: 1). This definition recognizes the art of critical ethical judgment in undergraduate research.

The above descriptions of undergraduate research writing agree that First Degree research projects are designed with the intent of creating new knowledge. Undergraduate research writing empowers students to create knowledge as well as communicate their findings. The students' benefit from the research experience of the supervisors who builds confidence, offers encouragement, and provides guidance and assistance for the students' future education and career development (CPT, 2000).

\section{Research Methods}

The focus of the study was on the influence of the use of social media on students' research skills. The purposive sampled population consisted of six hundred (600) students offering Educational Management at six different universities. The universities were randomly selected from the six geo-political zones in Nigeria. These include (i) Tai Solarin University of Education, Ogun State in the South-West (ii) Taraba State University, Taraba State in the North-East (iii) Ahmadu Bello University, Kaduna State in the North-West (iv) University of Ilorin, Kwara State in the North-Central (v) University of Nigeria, Enugu State in the South-East (xi) Ambrose Alli University, Edo State in the South-South. Three of the universities are owned by the Federal Government (UNILORIN, ABU and UNN ) while the other three are State owned universities (TASUED, AAU and TSU). These universities offer either Educational Management or Educational Administration and Planning; and also have facility for e-Learning.

A 20-question structured questionnaire was designed based on the literature that identified the general usage of social media by undergraduates offering Educational Management at the selected universities. It was administered to the students to elicit responses based on their perceptions of social media in general and, their view of using social media for research purposes. One hundred (100) students were randomly selected from each of the six universities.

Among the 600 questionnaires filled, 320 respondents $(53.3 \%)$ were female and 280 respondents $(46.7 \%)$ were male. This implies that there are more female students in the study than male students, though the margin of difference is small. The majority, $61 \%(\mathrm{n}=366)$ were between 18 and 25 years, $31.25 \%(\mathrm{n}=190)$ were between 26 and 30 , and $25 \%$ $(n=44)$ were 30 years and above. Large number of the respondents $(61 \%)$ as at 2014 when this paper was written falls into the Net Generation group who consume over 9 hours of social media daily. This could influence their 
responses on social media usage for research purposes. Out of the 600 respondents, $51.67(\mathrm{n}=310)$ were Christians while $48.33(\mathrm{n}=290)$ were Muslims. Thus, it is possible that the decisions of the respondents could be influenced by their gender, age, or religious affiliation.

All the respondents are aware and use one or more category of social media prior to responding to the questionnaire. They were further instructed about the eight categories of social media with examples indentified in the study. This is indicated below:

(1) Social networking sites (SNS)

Facebook - www.facebook.com

(2) Social bookmarking and sharing tools (SBST)

CiteULike - www.citeulike.com

(3) Blogging and Microblogging tools (BMT)

Wordpress - www.wordpress.org

(4) Virtual worlds (VW)

Second Life - www.secondlife.com

(5) Presentation sharing tools (PST)

Scribd - www.scribd.com

(6) Audio and Video Sharing tools (AVST)

YouTube - www.youtube.com

(7) Research and writing collaboration tools (RWCT)

Wikipedia: www. en.wikipedia.org

(8) Project management, meeting and collaboration tools (PMMCT)

Skype - www.skype.com

The category of social media was printed and distributed to familiarise the respondents with the research focus. The 20-question structured questionnaire was administered to the sample population. Data collected were analyzed using descriptive statistics like frequencies and percentages. Inferential statistics of Chi-square (X2) was used to test the only null hypothesis in the study.

\section{Findings and Results}

The numbers of students who use social media to source for research materials through social networking sites represent $2 \%(n=12)$ of the total population. No student used social bookmarking and sharing tools (SBST) in sourcing for materials. Large number of student $30.67 \%(n=184)$ relies on information from blogs to write their researches. No student made use of virtual world (VW) to source for research materials. $16 \%$ of the students $(n=96)$ made use of information from presentation and sharing tools (PST) particularly from Sribd. Also, 3\% $(n=18)$ of the students get data for their research from Audio and Video Sharing tools (AVST) such as Youtube. The most visited social media site used to source for research is Wikipedia categorized under Research and Writing Collaboration Tools (RWCT). 46.67\% $(n=280)$ of the respondents claim to use RWCT to source for information about their research topics. The last category which was project management, meeting and collaboration tools (PMMCT) had 1.66\% $(n=10)$ students using it for research purpose.

From the analysis above, large number of students goes to Wikipedia as their reliable source of information. By implication, students' reliance on Wikipedia as a reliable source of information could erode their research capability skills in the area of sourcing for quality materials for their researches.

Most students representing 34.16\% $(n=205)$ of the total study population turn to Facebook categorized under Social Networking Sites (SNS) when they need to generate ideas about areas of their research interest. 1.67\% $(n=10)$ of the students use CiteUlike placed under social bookmarking and sharing tools (SBST) in generating research ideas. 20\% $(n=120)$ of the students also browse blogs such as Wordpress or Blogger categorized under Blogging and Microblogging tools (BMT) to generate ideas about their research interest. $1.67 \%(n=10)$ use virtual world (VW) to get ideas about their researches. 5\% $(n=30)$ made use of Audio and Video Sharing tools (AVST) to generate ideas about their research. $5.83 \%(n=35)$ visit sites such as Wikipedia, WIkispaces, Pbworks classified under Research and Writing Collaboration Tools (RWCT) to generate ideas about their researches. And 1.67\% (n=10) use platforms such as Skype categorized under project management, meeting and collaboration tools (PMMCT) to generate ideas about their researches.

The findings indicate that Facebook is frequently used to generate ideas about areas of research interest.

Table 1. The social media frequently used to source for research materials

\begin{tabular}{|c|c|c|c|c|c|c|c|}
\hline & & & & & & \\
SNS & SBST & BMT & VW & PST & AVST & RWCT & PMMCT \\
Facebook & CiteULike & Wordpress & SecondLife & Scribd & YouTube & Wikipedia & Skype \\
$\mathrm{n}=12$ & $\mathrm{n}=0$ & $\mathrm{n}=184$ & $\mathrm{n}=0$ & $\mathrm{n}=96$ & $\mathrm{n}=18$ & $\mathrm{n}=280$ & $\mathrm{n}=10$ \\
$2 \%$ & $0 \%$ & $30.67 \%$ & $0 \%$ & $16 \%$ & $3 \%$ & $46.67 \%$ & $1.66 \%$ \\
\hline
\end{tabular}

Table 2. The social media frequently used to generate ideas about areas of research interest

\begin{tabular}{|c|c|c|c|c|c|c|c|}
\hline & & & & & \\
SNS & SBST & BMT & VW & PST & AVST & RWCT & PMMCT \\
Facebook & CiteULike & Wordpress & SecondLife & Scribd & YouTube & Wikipedia & Skype \\
$n=205$ & $n=10$ & $n=120$ & $n=10$ & $n=30$ & $n=35$ & $n=180$ & $n=10$ \\
$34.16 \%$ & $1.67 \%$ & $20 \%$ & $1.67 \%$ & $5 \%$ & $5.83 \%$ & $30 \%$ & $1.67 \%$ \\
\hline
\end{tabular}


Table 3. The social media frequently used to develop creative writing skills

\begin{tabular}{|c|c|c|c|c|c|c|c|}
\hline SNS & SBST & BMT & VW & PST & AVST & RWCT & PMMCT \\
Facebook & CiteULike & Wordpress & SecondLife & Scribd & YouTube & Wikipedia & Skype \\
$n=60$ & $n=10$ & $n=330$ & $n=0$ & $n=80$ & $n=0$ & $n=120$ & $n=0$ \\
$10 \%$ & $1.67 \%$ & $55 \%$ & $0 \%$ & $13.33 \%$ & $0 \%$ & $20 \%$ & $0 \%$ \\
\hline
\end{tabular}

In developing creative research writing skills, $10 \%(n=60)$ used social networking sites (SNS) such as Facebook; 1.67\% $(n=10)$ used social bookmarking and sharing tools (SBST) such as CiteuLike; 55\% (n=330) used blogging and microblogging tools (BMT) such as Wordpress; none used virtual world (VW); $13.33 \%(n=80)$ used presentation and sharing tools (PST) such as Scribd; none used Audio and Video Sharing tools (AVST); 20\% $(n=120)$ used Research and Writing Collaboration Tools (RWCT) such as Wikipedia; and, none used project management, meeting and collaboration tools (PMMCT).

The findings indicate that Wordpress or Blogger, classified under blogging and microblogging tools (BMT) is frequently used to develop creative writing skills.

\section{Research hypothesis}

$\mathrm{Ho}^{1}=$ There is no significant difference between students' reliance on social media and dwindling research skills

Inferential statistical tool chi square $\left(\chi^{2}\right)$ was used for the analysis.

Table 4. Chi square $\left(\chi^{2}\right)$ analysis of responses

\begin{tabular}{|c|c|c|c|}
\hline 1 & $95(16.1)$ & $98(16.8)$ & $193(32.1)$ \\
\hline 2 & $13(2.15)$ & $13(2.15)$ & $26(4.3)$ \\
\hline 3 & $9(1.5)$ & $9(1.5)$ & $18(3.0)$ \\
\hline 4 & $89(14.3)$ & $87(14.5)$ & $173(28.8)$ \\
\hline 5 & $21(3.8)$ & $20(3.0)$ & $41(6.8)$ \\
\hline 6 & $47(7.53)$ & $47(7.53)$ & $94(15.6)$ \\
\hline 7 & $26(4.1)$ & $29(5.0)$ & $55(9.1)$ \\
\hline
\end{tabular}

$\mathrm{X}^{2} \mathrm{cal}=6.72$

$\mathrm{X}^{2} \mathrm{tab}=12.592$

$\mathrm{df}=6$

$\mathrm{P}>.05$

Since $X^{2}$ cal of 6.72 is $<X^{2}$ tab of 12.592 at .05 level of significance of $\mathrm{df}(6)$, the null hypothesis is accepted. It is concluded that there is a strong relationship between students' reliance on social media and dwindling research skills.

\section{Conclusions}

From the statistical analysis of the sample, it is evident that three critical areas where the use of social media affects undergraduates' research skills are: on their source of information, generation of research ideas and creative writing skills. These are summarized below:

(1) Undergraduates' reliance on social media tools such as Wikipedia as their major source of information has serious implications for their researches. First, their source of information becomes inadequate, one-sided and inaccurate. Second, they tend to develop dwindling research skills, and increasing poor ability to use the library or conduct field work research. This finding corresponds with the findings of Menchen and Hargittai (2011: 24-30) that 8 in 10 students went to Wikipedia to obtain background information or a summary about a topic. Unfortunately, most academics look down on the open source online encyclopaedia primarily because the data can be posted, edited and manipulated by anyone. This, however is not to discredit Wikipedia as most of the content have undergone series of editing by professionals. Nevertheless, students' over-reliance on Wikipedia posses serious challenge to their research skills, especially in the area of sourcing for information.

(2) Undergraduates' use of social media tools such as Facebook to generate ideas about areas of research interest enhances their research works. First, the medium serves as a platform for meeting other scholars and discussing new ideas about a specific academic topic. Second, undergraduates use the platform to hear the views of professionals on a given topic, opening new doors for online interviews. Third, opinion poll in the social networking site is used to generate ideas about areas of research interest. This corresponds with the findings of Ogedengbe, Emmanuel \& Musa (2012: 789) that Facebook is the most popular Social Network Site (SNS) among undergraduates and is most useful in interaction, active participation, collaboration, critical thinking and information sharing. Despite its usefulness in generating research ideas, most undergraduates soon forget their purpose of using the medium for research and start updating their status, checking what friends are doing and chatting. This diversion of attention remains the biggest obstacle of using social networking sites for research purpose. In fact, Facebook has not made significant inroads into classroom usage because of this factor (Roius et al., 2011: 962).

(3) Undergraduates' use of social media tools such as Wordpress and Blogger enhances their creative writing skills. This agrees with the findings of Pat Thomson (2013) that having to write for ordinary readers will help students to write in plain English, clarify ideas, enhance reputations and expand knowledge as well as the audience.

(4) Other social media platforms such as CiteuLike classified under social bookmarking and sharing tools 
(SBST); SecondLife grouped under Virtual Worlds (VW); and, Skype placed under Project management, meeting and collaboration tools (PMMCT) are yet to be fully explored by undergraduates for research purpose.

\section{Recommendations}

This study assessed the influence of social media usage on research skills of undergraduates. The literature review shows that not much has been published on the relationship between social media usage and research skills of undergraduates. Also, the research was restricted to a limited number of 600 respondents. This implies that it cannot represent millions of social media users who employ the technology for research purpose. Considering these limitations, there are many aspects that have not been investigated and that could warrant further research into social media usage among students in Nigeria. We therefore suggest that:

(1) More comprehensive quantitative studies need to be undertaken exploring other ways by which social media affects undergraduates research skills, particularly in the sourcing for research materials;

(2) Studies could also be conducted to determine ways in which social media, particularly Facebook categorized under Social Networking Sites (SNS), Youtube placed under Audio and Video Sharing tools (AVST) and Wikipedia classified under Research and Writing Collaboration Tools (RWCT) can be used to generate research ideas;

(3) Research could be conducted to determine how Social Networking Sites (SNS), Blogging and Microblogging Tools (BMT) and, Research and Writing Collaboration Tools (RWCT) could become more useful in developing students' creative writing skills through multi-tasking researches; and,

(4) Universities should build and integrate interactive learning tools as well as links to research databases to make the use of social media relevant to students' research needs.

\section{REFERENCES}

[1] Adrienne Showman, et al (2013) Five Essential Skills for Every Undergraduate Researcher. University of Central Florida. Vol. 33, No. 3.

[2] Ajewole Olaniyi Olowu, and Fasola Omobolanle Seri (2012) "A Study Of Social Network Addiction Among Youths In Nigeria". In Journal of Social Science and Policy Review, Volume 4,

[3] Bryer, T. \& Zavattaro, S. (2011). "Social media and public administration: Theoretical dimensions and introduction to symposium". In Administrative Theory \& Praxis, 33(3),
$325-340$.

[4] Bunco, R. (2011) "Too much face and not enough books: The relationship between multiple indices of Facebook use and academic performance". Computers in Human Behavior, doi: 10.1016/j.chb.2011.08.026

[5] Facebook (2013), "Facebook Reports Second Quarter 2013 Results". Web. Accessed: http://investor.fb.com/releasedetai 1.cfm?ReleaseID=780093. Date: $27 / 1 / 2014$

[6] Farzana Shafique, Mushahid Anwar \& Mahe Bushra (2010) "Exploitation of social media among university students: A case study". Webology, Volume 7, Number 2, Accessed: http://www.webology.org/2010/v7n2/a79.html. Date: $27 / 1 / 2014$

[7] Creswell, J. W. (2008). Educational Research: Planning, conducting, and evaluating quantitative and qualitative research (3rd ed.). Upper Saddle River: Pearson.

[8] CPT (2002) "Characteristics of Undergraduate Research," American Chemical Society's Committee on Professional Training Newsletter.

[9] John Willison (2009) "A Handbook for Research Skill Development and Assessment in the Curriculum", Centre for Learning and Professional Development, University of Adelaide.

http://www.adelaide.edu.au/rsd/docs/rsd_Handbook_Dec09. pdf. Date: $27 / 1 / 2014$

[10] Jaclyn Cabral (2011) "Is Generation Y Addicted to Social Media?" The Elon Journal of Undergraduate Research in Communications. Vol. 2 (1).5-14 spring 2011.

[11] Junco, R., \& Cotten, S. (2012). "The relationship between multitasking and academic performance”. In Computers \& Education, 59(2), 505-514

[12] Kaplan Andreas M., Haenlein Michael (2010). "Users of the world, unite! The challenges and opportunities of social media". In Business Horizons 53 (1). p.61.

[13] Kirschner, P., \& Karpinski, A. (2010). "Facebook and academic performance". In Computers in Human Behavior, 26(6), 1237-1245.

[14] Menchen Trevino, E. \& Hargittai, E. (2011). Young Adults' Credibility Assessment of Wikipedia". In Information, Communication and Society . 14(1):24 - 51 .

[15] Ogedebe, P. M., Emmanuel, J. A., \& Musa, Y.(2012) A survey on Facebook and Academic Performance in Nigeria Universities. In International Journal of Engineering Research and Applications (IJERA) Vol. 2, Issue 4

[16] Oluwatoyin A. Enikuomehin (2011), "ICT, CGPA: Consequences of Social Networks In An Internet Driven Learning Society." In International Journal of Computer Trends and Technology, Vol 2, Issue 2.

[17] Onyeka Ndidi Camilia, Sajoh Dahiru Ibrahim \& Bulus Lucy Dalhatu (2013), The Effect of Social Networking Sites Usage on the Studies of Nigerian Students The International Journal Of Engineering And Science (IJES) Volume, 2 Issue 7, Pages 39-46, 2013

[18] Pat Thomson and Inger Mewburn (2013)" Guardian Professional, Monday 2 December 2013 Why do academics blog? It's not for public outreach, research shows." 
Web.http://www.theguardian.com/higher-education-network /blog/2013/dec/02/why-do-academics-blog-research. Date: 27/1/2014

[19] Qbeemedia, "Did you know? Social Media interesting facts!", Accesed: http://www.qbeemedia.com/facts Date: 27/01/2014

[20] Qingya Wang, Wei Chen \& Yu Liang (2011) "The Effects of Social Media on College Students. MBA Student Scholarship". Paper 5. Accessed:

http://scholarsarchive.jwu.edu/mba_student/5.

Date: $27 / 1 / 2014$

[21] Sana Rouis, Moez Limayem, Esmail Salehi-Sangari (2011) "Impact of Facebook Usage on Students' Academic Achievement: Roles of Self-Regulation and Trust".
Electronic Journal of Research in Educational Psychology, 9(3), 961-994

[22] Shuttleworth, Martyn (2008). "Definition of Research". Experiment Resources. Accessed http://www.Experiment-Research.com. Date: 27/1/2014

[23] Social Media Online. (2011). "Social Media" Accessed: www.creativemediafarm.com/information/glossary. Date: $27 / 1 / 2014$

[24] Wayne C. Booth, Gregory G. Colomb, Joseph M. William (2009), The Craft of Research, Third Edition. Chicago: The University of Chicago Press

[25] Wenzel, T. J. "What is Undergraduate Research?," In Council on Undergraduate Research Quarterly,1997, 17, 163. 